\title{
The occurrence of cryptosporidiosis and amoebiasis among HIV infected female sex workers with symptomatic diarrhoea
}

\author{
Singh $\mathrm{T}^{1 *}{ }^{*}$, Singh $\mathrm{L}^{2}$ \\ DOI: https://doi.org/10.17511/ijmrr.2020.i02.05 \\ 1* Th. Nabakumar Singh, Associate Professor, Department of Microbiology, Regional Institute of Medical Sciences (RIMS), Imphal, Manipur, \\ India. \\ 2 L. Anand Singh, Research Scientist II, State Level VRDL, Department of Microbiology, Regional Institute of Medical Sciences, Imphal, \\ Manipur, India.
}

Objectives: Manipur is one of the high HIV prevalence states of India.Quite a good number of HIV infected females are indulged in the profession of sex workers. These female sex workers (FSWs) are experiencing a number of gastrointestinal related disorders including diarrhoea caused by a wide variety of pathogens, including parasites. Therefore, the present study is being undertaken with a view assessing the occurrence of enteric parasites, especially Cryptosporidium sp and Entamoeba histolytica towards their involvement as the diarrhoeagenic agent(s) in these groups of patients. Materials and Methods: A cross-sectional study was conducted in the Department of Microbiology, Regional Institute of Medical Sciences (RIMS) Hospital, Imphal, Manipurfrom $1^{\text {st }}$ January to $31^{\text {st }}$ December 2018. The study group included54 HIV seropositive female sex workers with symptomatic diarrhoea. Stool sample(s) preserved in 2.5\% K2Cr2O7for Cryptosporidium sp and $10 \%$ buffer formalin for Entamoeba histolytica and other classical parasites were collected for this study. Results: The present study reveals that out of the selected 54 HIV positive FSWs screened for the presence of enteric parasitosis, $16(29.62 \%)$ individuals were found positive for three parasitic infections- cryptosporidiosis, amoebiasis and hookworm infection. Both mixed infection (31.25\%) and single infection $(68.75 \%)$ were observed among the patients. Single infection with Cryptosporidium sp and Entamoeba histolytica were observed in $5(31.25 \%)$ and $6(37.5 \%)$ patients respectively. Patients in the age group of $25-30$ and 30-35 years were observed to have been more infected. Conclusion: The study reveals that intestinal parasitic infection caused by Cryptosporidium sp and Entamoeba histolytica are prevalent among the present study group of HIV infected female sex workers.

Keywords: Female sex worker, HIV, Enteric parasites

\section{Corresponding Author}

Th. Nabakumar Singh, Associate Professor, Department of Microbiology, Regional Institute of Medical Sciences (RIMS), Imphal, Manipur, India. Email: nabakr@rediffmail.com
How to Cite this Article

To Browse

Singh TN, Singh LA. The occurrence of cryptosporidiosis and amoebiasis among HIV infected female sex workers with symptomatic diarrhoea. Int J Med Res Rev. 2020;8(2):164-168. Available From

https://ijmrr.medresearch.in/index.php/ijmrr/article/ view/1155

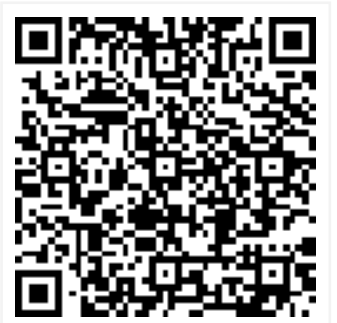

Manuscript Received 2020-03-17

Conflict of Interest No

(c) 2020 by Th. Nabakumar Singh, L. Anand Singh and Published by Siddharth Health Research and Social Welfare Society. This is an Open Access article licensed under a Creative Commons Attribution 4.0 International License https://creativecommons.org/licenses/by/4.0/ unported [CC BY 4.0].

Accepted 2020-04-06

iew Round 2020-03-27

unding 


\section{Introduction}

Manipur, a state in the North-east of India have 31,549 people living with HIV (PLHIV), out of which 14,187 are women, as per NACO, 2018 [1]. Moreover, Manipur is also reporting an increasing number of sexual transmissions of HIV through female sexual partners of injecting drug users (IDUs), commercial sex workers (CSWs), homosexuals and migrant workers. Various workers have reported the association of a number of opportunistic and non-opportunistic parasites with the HIV/AIDS patients $[2,3,4]$. Opportunistic coccidian parasite like Cryptosporidium parvum and other non-opportunist parasites like Entamoeba histolytica E. dispar, Cyclospora belli, Cyclosporacayetanensis, Ascarislumbricoides, Trichuristrichiura, Enterobiusvermicularis, hookworm and Strongyloidesstercoralis is reported to be prevalent among the HIV infected patients of the state $[5,6,7,8,9,10,11,12]$. These enteropathogenic parasites cause a number of gastrointestinal disorders including diarrhoea in these patients. Diarrhoea is reported to be one of the leading causes of morbidity and mortality among the HIV/AIDS patients and has been included in the clinical case definition of AIDS by NACO and WHO. Moreover, Cryptosporidium a ssociated/induced diarrhoea is one of the important health problems usually encountered among the people living with HIV (PLHIV). Till date, no research data or published report is available with regard to the occurrence of intestinal parasitic infections and especially of diarrhoea causing opportunistic coccidian protozoan parasite - Cryptosporidiumsp and the amoebic parasite Entamoebahistolytica among the HIV infected female sex workers of the state. Therefore, the present work is carried out with a view to assessing the prevalence of intestinal parasites, especially of Cryptosporidium sp and E. histolytica amongthe group of female sex workers (FSWs) who had complained of experiencing gastrointestinal disorders including symptomatic diarrhoea.

\section{Materials and Methods}

A Cross-sectional study was conducted in the Department of Microbiology, Regional Institute of Medical Sciences (RIMS) Hospital, Imphal, Manipur, India over a period of one year (1st January to 31st December 2018). Samples were collected from the clients through the agency of women's drug deaddiction on and rehabilitation centres of two districts of Manipur namely Thoubal district and
Churachandpur district, working for the welfare of the HIV/AIDS affected women. A total of 54 HIV positive female sex workers (FSW), with symptomatic diarrhoea, were enrolled for the present study. Among these 54, 22 belongs to Meitei community and 32 were the tribal community. The age group of the patients were categorized into four groups, viz 20-25 years, 25-30 years, 30-35 years and $\geq 35$ years. Stool samples from 54 HIV positive female sex workers (FSW), with symptomatic diarrhoea, were collected in sterile containers containing $2.5 \%$ potassium dichromate $\left(\mathrm{K}_{2} \mathrm{Cr}_{2} \mathrm{O} 7\right)$ solution and $10 \%$ buffer formalin

Inclusion criteria: Subjects with HIV positive female sex workers (FSW), with symptomatic diarrhoea were taken into consideration.

Exclusion criteria: Subjects with HIV positive female sex workers (FSW) with asymptomatic diarrhoea, HIV negative female sex workers (FSW) with symptomatic diarrhoea, unwilling HIV positive female sex workers (FSW) with symptomatic diarrhoea.

The study was approved by the Research Ethics Board of Regional Institute of Medical Sciences (RIMS), a tertiary Hospital, Imphal, Manipur, India. Written consents were obtained from all participants. All patients were subjected to a detailed clinical history about their signs and symptoms as well as brief health, hygienic and socioeconomic history was also evaluated. Detection, recovery and identification of the parasite (s) in the stool samples were done by employing the techniques of the normal saline method, iodine wet preparation method and formalin ethyl acetate concentration technique in case of classical parasites and especially of Entamoeba histolytica, by using the faecal samples preserved in $10 \%$ buffer formalin $[13,14]$. While modified Sheather's sucrose flotation technique [15] was employed for concentrating the oocyst of Cryptosporidium, modified ZiehINeelsen (Z-N) staining technique was adopted for the detection of Cryptosporidium sp [16]. The cyst of Entamoeba histolytica was identified and confirmed based on the presence of a) 1,2 or 4 nuclei b) glycogen mass $\mathrm{c}$ ) chromatoid bodies with rounded ends and finally by measuring the dimension of the cyst (range $=10-20 \mu \mathrm{m}$, usual $=12-15 \mu \mathrm{m}$ ) with the help of an ocular micrometre and a calibrated high powered compound microscope (Nikon E - 200). For the detection of oocyst of Cryptosporidium, all the slides stained with modified $\mathrm{Z}-\mathrm{N}$ were first examined 
With a 40x objective to detect the bright red/orange, round or oval structures with a clear halo. These structures measuring $4-5 \mu \mathrm{m}$ in diameter were confirmed as Cryptosporidium under oil immersion (100x) when the characteristic clear centre with darker periphery or dark centre with the light periphery, depending on the arrangement of the sporozoites were identified.

\section{Results}

Of the selected 54 HIV positive diarrhoeal FSWs examined for the presence of enteric parasitic infections, especially of Entamoeba histolyticaand Cryptosporidium, 16(29.62\%) individuals were found positive for the three parasitic infections, i.e. cryptosporidiosis, amoebiasis and hookworm infection (Table I).

During the present study, while the mixed infection was encountered in $31.25 \%$, the single infection was observed in $68.75 \%$. While mixed infection with Cryptosporidiumsp and Entamoeba histolytica was observed in $4(25 \%)$ patients, only one patient $(6.25 \%)$ was found to have been suffering from the dual infection of Entamoeba histolytica and hookworm.

While single infection with Cryptosporidium was observed in only $5(31.25 \%)$ patients, a single infection with Entamoeba histolyticawas observed in $6(37.5 \%)$ patients. In this study, while the age group 25-30 years and 30-35 years were observed to have more number of patients with parasitic infections with a cluster of 5 patients in each age group, only 2 patients in the age group of $\geq 35$ years were found to have parasitic infections.

On X2analysis, it was observed that the age group 25-30 yrs and 30-35 yrs were found to be independent of the two diseases namely cryptosporidiosis and amoebiasis $(p<0.05)$. It was statistically significant.

Table-I: Distribution of Cryptosporidiumspand E. histolytica among the studied population (n = 16)

\begin{tabular}{|l|l|l|l|l|l|l|l|l|}
\hline \multirow{2}{*}{ Name of the Parasite (s) } & \multicolumn{7}{|c|}{ Age in years } \\
\cline { 2 - 9 } & \multicolumn{7}{|c|}{$(20-25)(25-30)(30-35)(\geq 35)$} \\
\cline { 2 - 9 } & T & M & T & M & T & M & T & M \\
\hline Cryptosporidiumsp & 1 & 0 & 1 & 1 & 1 & 0 & 1 & 0 \\
\hline Cryptosporidiumsp +E. histolytica & 0 & 0 & 2 & 0 & 0 & 1 & 1 & 0 \\
\hline E. histolytica + Hookworm & 0 & 0 & 0 & 0 & 1 & 0 & 0 & 0 \\
\hline E. histolytica & 1 & 2 & 0 & 1 & 0 & 2 & 0 & 0 \\
\hline
\end{tabular}

*T - Tribal, M - Meitei

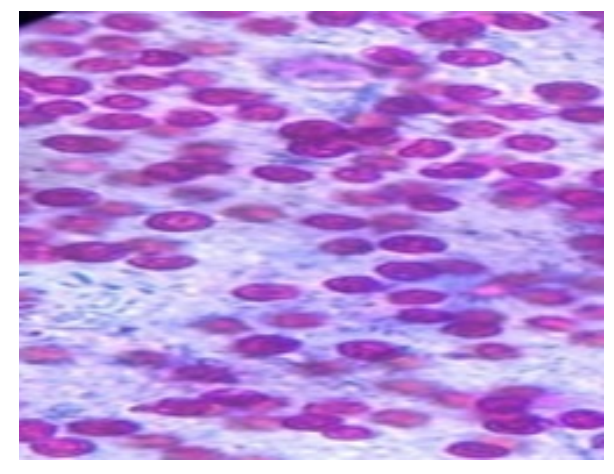

Fig-1: Oocyst of Cryptosporidiumsp(Modified Sheather's sucrose floatation technique concentrated oocysts Stained with Modified Ziehl Neelsen staining technique, 100x)

\section{Discussion}

Literature review reveals the association of a number of intestinal parasites with the HIV/AIDS patients and especially with HIV positive injecting drug users or AIDS patients. However, no published data or paper pertaining to the enteric parasites associated with the HIV positive female sex workers/commercial sex workers of the state is traceable or available. The present report is probably the first documented record of such type of study in the state of Manipur. Of the 32 tribal community patients examined for the presence of enteric parasitic infections, only $9(28.12 \%)$ were found positive for parasitic infections. Likewise, of the 22 meitei community patients, only 7 (31.81\%) individuals were harbouring the pathogenic parasites. Of the 16 patients found positive for parasitic infections, there were 13 married women (which consisted of 8 tribal and 5 meitei community ) and 3 unmarried women (all were tribal). Of the 8 tribal female sex workers, 3 were widow and 3 were injecting drug users (IDUs). The remaining two tribal women admitted having acquired the virus from their spouses who according to them were IDUs. Of the five married meitei women (FSW), two had admitted of having a pre-marital physical relationship with their boyfriends, whom they were doubtful about their HIV status, while they were studying outside the state and the remaining 3 had claimed that they might have acquired the virus only after getting married and most probably from their spouses. All the clients/patients had been engaging in this profession for more than 5 years. They all reported having multiple sex partners with a minimum of 12 clients per month. All the married FSWs had a family history of either a previous broken marriage or early deceased of the husband. 
Each of the two widows was having a child while the remaining widow was issueless. They are not the regular practitioners of this profession but practise it just as a part-time job. They themselves are also engaged with other small livelihood business. Some of them work as weavers, vegetable growers, roadside vendors, fruit sellers and as casual labourers in brickfields, stone crushing and building construction firms etc. Some even work as domestic helpers. A small number of participant(s)/clients were enrolled for the present investigation. The reason for which included non-existence of brothel house, as well as the less participatory tendency of the clients (FSWs) as most of the clients, were drug addicts and belonged to the low socioeconomic group. Above all, as mentioned earlier, almost all the clients practise this profession as part-time job towards mending the domestic financial hardships. All these factors led to the low number of participants in the present study programme. As far as the present study is concerned, it can be inferred that Entamoeba histolytica and Cryptopsoridiumare prevalent in these patients who had complained of symptomatic diarrhoea. Moreover,the present observation confirms that these protozoan parasites constitute one of the important diarrhoeagenic agents associated with this group of patients in Manipur. Earlier worker [9] have reported a prevalence rate of Cryptosporidium within the range of $36.7 \%$ to $69.2 \%$ among the HIV infected diarrhoeal patients of the state. In contrast to this report, other workers have reported a distributional variation of this coccidian parasite within the range of $3.33 \%$ to $25 \%$ depending on the topographical, climatic and regional variation including the sociobehavioural and socioeconomic status of the studied population $[17,18,19,20]$. There are also reports that in India, $47 \%$ of AIDS patients experienced chronic diarrhoea in 1997, although the spectrum of pathogens involved was not properly investigated [21]. In the case of the present investigation, the patients might have acquired these parasitic infections through the known transmission mechanisms. Although all the patients in the studied population complained of experiencing diarrhoea, no otherparasitic agent was detected in most of them. In fact, diarrhoea in HIV/AIDS patients may also be of fungal, viral or bacterial origin. Moreover, other potential causes of diarrhoea among patients with pathogen negative diarrhoea may be due to HIV induced enteropathy and fat malabsorption. In HIV/AIDS patients, it has been reported that whenever pathogens are found in HIV related diarrhoea, protozoan infections dominate over the
Bacterial causes [22,23]. In spite of these observations, more studies should be encouraged to ascertain the possibility of involving any other pathogen other than enteric parasites in HIV related diarrhoea in the female sex workers (FSWs) of the state towards maintaining a quality life for these people living with high-risk behaviour.

\section{Conclusion}

Diarrhoea is reported to be one of the leading causes of morbidity and mortality among HIV/AIDS patients. The present study reveals that intestinal parasitic infection caused by Cryptosporidium sp and Entamoeba. histolytica are prevalent among the HIV infected FSWs of the state. Therefore, regular monitoring of this group of patients for the presence of enteric parasites and also for assessing the involvement of other diarrhoeagenic biological agents (if any), other than parasite(s) will be of immense value towards providing proper management as well as in suggesting prophylactic measures so that the motto of living well with HIV/AIDS can be accomplished for these people with high-risk behaviour.

\section{What does the study add to the existing knowledge}

These female sex workers (FSWs) are experiencing a number of gastrointestinal related disorders including diarrhoea caused by a wide variety of pathogens, including parasites. Therefore, assessing of the occurrence of enteric parasites, especially Cryptosporidium sp and Entamoeba histolytica towards their involvement as the diarrhoeagenic agent(s) in these groups of the patient is of utmost necessity to improve the quality of life of people living with HIV/AIDS.

\section{Author's contribution}

Dr. Th. Nabakumar Singh: Framework of study design, data analysis, proofreading Dr. L. Anand Singh: Study design, data analysis, paper writing, typing

\section{Reference}

01. NACO, HIV Estimations, 2017. Technical Report, New Delhi, NACO, Ministry of Health and Family Welfare, Government of India. National AIDS Control Organization and ICMR- National Institute of Medical Statistics. 2018. Available at [Article] [Crossref] 
02. Cimerman S, Cimerman B and Lewis DB. Prevalence of intestinal parasitic infection inpatients with Acquired Immunodeficiency Syndrome in Brazil. Int J Inf Dis. 1999;3(4)203-06.

doi: [Article] [Crossref]

03. Nath R, Saikia L, Sen SS, Borthakur AK. Clinical profile of HIV/AIDS in Assam Poster presentation (PM-10), Int Conf on Opportunistic. Pathogens in AIDS (ICOPA), New Delhi. 2006; 27-29. [Crossref]

04. Patel $M$, Patel $R$, Paliwal M. Intestinal parasitic infections in HIV-1 seropositive individuals and its correlation with CD4 cell count in a tertiary care teaching hospital, Gujarat. Int J Biomed Adv Res. 2017;8(4)174-178. doi: [Article] [Crossref]

05. Anand L, Brajachand Ng, Dhanachand Ch. Cryptosporidiosis in HIV infection. J Comm Diseases. 1996;28(4)241-244.

[Crossref]

06. Anand L, Dhanachand Ch, Brajachand Ng. Prevalence and epidemiologic characteristics of opportunistic and non-opportunistic intestinal parasiticinfections in HIV positive patients in Manipur. J Comm Diseases. 1998;30(1)19-22. [Crossref]

07. Agarwal A, Ningthouja S, Sharma D, Mohen $Y$ and Singh $\mathrm{Ng}$ B. Cryptos poridium and HIV. J Ind Med Assn. 1998;96(9)276 -277.

[Crossref]

08. Dhanachand Ch, Anand L. Helminthic infections in HIV/AIDS patients, In Helminthology in India; Edited by Prof ML Sood. International Book Distributors, Dehradun, India. 2003.

[Crossref]

09. Singh LA, Das SC, Baruah I. Enteric parasites in patients with HIV infection. J Parasitol App Animal Biol. 2004a;13(1 and 2)55-64.

[Crossref]

10. Singh LA, Chinglensana $L$, Singh Ng $B$, Singh $H L$, Singh YI. Helminthiasis in HIV infection- A brief report from Manipur (India). J Comm Diseases. 2004b;36(4)293-296.

[Crossref]

11. Devi PP, Rebachandra H, Brajachand SN, Nabakumar TH. Strongyloides stercoralis infection in an HIV positive patient - A case report from RIMS, Imphal, Manipur. J Comm Diseases. 2010;42(3)231-234.

[Crossref]
12. Singh Th N, Devi $H R$, Singh $L A$. Occurrence of Hookworm-Whipworm co-infection among the HIV/AIDS patients of Noney district of Manipur, India. IOSR J Dent Med Sci. 2018;17(10)15-18. [Crossref]

13. World Health Organization (WHO). Bench Aids for the diagnosis of intestinal parasites, Reprinted copy. Geneva- WHO. 2003. Available at [Article] [Crossref]

14. World Health Organization (WHO). Manual of basic techniques for a health laboratory. 2nd Edition, Geneva. 2003.

Available at [Article] [Crossref]

15. John D T and Petri Jr, W A. Examination of stool specimens (Chapter 14), In Markell and Voge's Medical Parasitology. 9th Edition, Elsevier. 2009;pp 407-408.

[Crossref]

16. Smith $H$ V. Intestinal Protozoa, In Medical Parasitology, A Practical Approach, Edited by Gillespie, SH andHawkey, P M. Oxford University Press, Reprinted. 2002;pp 79-117.

[Crossref]

17. Talib S H, Singh J. A study on opportunistic enteric parasites in HIV seropositive patients. Ind J Pathol Microbiol. 1998;41(1)31-37.

[Crossref]

18. Mukhopadhya A, Ramakrishna B S, Gangadeep $K$, Pulimood AB, Mathan MM, Zachariah A. Enteric pathogens in Southern Indian HIV infected patients with and without diarrhoea. Ind J Med Res. 1999;109;85-89.

[Crossref]

19. EscobedoA A, Nunez FA. Prevalence of intestinal parasites in Cuban acquired immunodeficiency syndrome (AIDS) patients. Acta Tropica. $1999 ; 72(1) 125-130$. doi: [Article] [Crossref]

20. Bajaj R, Arora U, Aggarwal A. Prevalence of intestinal protozoa in HIV seropositive patients with special reference to Cryptosporidiosis. J Parasitic Diseases. 2003;27(1)29-32.

[Crossref]

21. Misra SN, Sengupta D and Satpathy SK. AIDS in India- Recent trends in opportunistic infection. South East Asian J Trop Med Public Health. $1998 ; 29(2) 373-376$.

[Crossref] 
23. Navin TR, Weber R, Vugia DJ, Rimlan D, Roberts JM, Addis DG, et al. Declining CD4 T-lymphocyte counts are associated with Increased risk of enteric parasitosis and chronic diarrhea- Results of a 3-year longitudinal study. J AIDS Human Retrovirol. 1998;20(2)154-159. doi: [Article] [Crossref]
24. Weber $R$, Ledergerber $B$, Zbinden $R$, Altwegg $M$, Pfyffer GE, Spycher MA, et al. Enteric infections anddiarrhea in human immunodeficiency virus infected persons. Arch Intern Med. 1999;159(13)1473-1480. doi: [Article] [Crossref] 